\title{
Synthesis and Properties of Interpolymer Complexes Based on Chitosan and Sulfated Arabinogalactan
}

\author{
N. V. Slyusarenko ${ }^{a *}$, N. Yu. Vasilieva ${ }^{a}$, A. S. Kazachenko ${ }^{b}$, M. A. Gerasimova ${ }^{a}$, \\ A. S. Romanchenko ${ }^{b}$, and E. A. Slyusareva ${ }^{a}$ \\ a Siberian Federal University, Krasnoyarsk, 660041 Russia \\ ${ }^{b}$ Institute of Chemistry and Chemical Technology, Krasnoyarsk Scientific Center, \\ Siberian Branch, Russian Academy of Sciences, Krasnoyarsk, 660036 Russia \\ *e-mail:sci_box@mail.ru
}

Received July 25, 2019; revised November 7, 2019; accepted November 22, 2019

\begin{abstract}
Synthetic interpolymer complexes based on chitosan and arabinogalactan with a different degree of sulfation $(7.7-40.8 \%)$ stable for 30 days are synthesized. The resulting complexes are characterized by scanning electron microscopy, IR spectroscopy, dynamic light scattering, and $\zeta$-potential electrophoretic measurements. The main mechanism of complex formation is considered in terms of the electrostatic bonding of polyions. New complexes show promise as biosorbents and drug delivery systems.
\end{abstract}

DOI: $10.1134 / \mathrm{S} 1560090420020050$

Among natural polysaccharides, chitosan, a product of chitin deacetylation, occupies a unique place. It has a polycationic nature in acidic media, is biodegradable, and shows antibacterial, bioadhesive, and healing properties [1]. The formation of hydrophilic nonstoichiometric interpolymer complexes (IPC) based on chitosan allows one not only to preserve the polymer properties important for biomedicine but also to supplement them with the properties inherent to particles: mobility, increased effective surface, and filtration. This makes it possible to use them as biosorbents or drug delivery hicles [2-5]. The cationic nature of chitosan enables one to form complexes (they are also called polyelectrolyte complexes) with various anionic polysaccharides, for example, heparin, carrageenans, chondroitin sulfate, hyaluronate, and others [6-12]. The creation of new interpolymer complexes that advantageously combine the properties of particles and biopolymers continues, and colloidal stability is an important issue in their practical application.

This work highlights the possibility of creating nonstoichiometric submicron interpolymer complexes based on chitosan and sulfated arabinogalac$\tan$ (SAG). The source of arabinogalactan is mainly larch wood. The sulfation of arabinogalactan significantly expands its range of application. For example, anionic activity allows the formation of polyelectro- lyte complexes with polycations, and hypolipidemic and anticoagulant properties provide the opportunity to apply it as a heparinoid analog or as an antimicrobial agent $[13,14]$. The joint successful use of these two polysaccharides for tissue engineering was demonstrated by the creation of highly porous sponges [15].

The properties of the complexes obtained from arabinogalactan with varying degrees of sulfation were studied by scanning electron microscopy and dynamic light scattering, and the results of IR measurements of interpolymer complexes (size and $\zeta$-potential) and of the starting polymers forming IPCs were presented. New colloid-stable submicron complexes based on chitosan and SAG are a promising biologically active material because they combine the unique properties of biopolymers included in its composition [16-18].

\section{EXPERIMENTAL}

The starting polymers for the synthesis of IPCs was low-viscosity chitosan from the shell of a shrimp with molecular weight $M=(20-200) \times 10^{3}$ manufactured by Sigma-Aldrich 


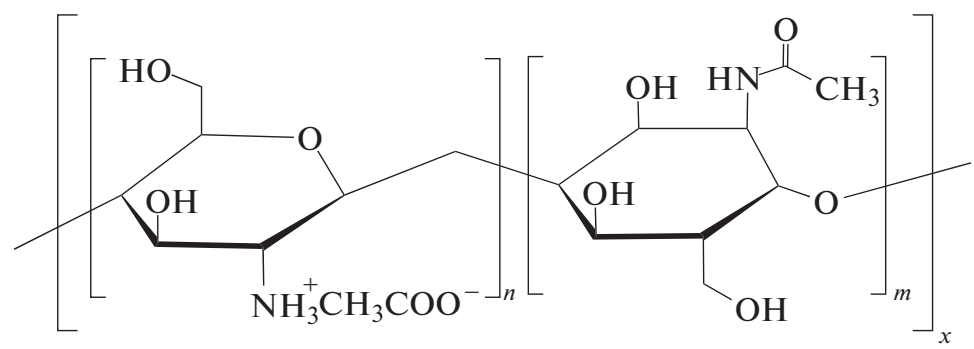

and arabinogalactan of Siberian larch wood (Larix sibirica Ledeb.) with an average molecular weight of $M \sim 17 \times$ $10^{3}$ provided by OOO Chemistry of Wood (Russia) under the name of the FibrolarS preparation [19]:

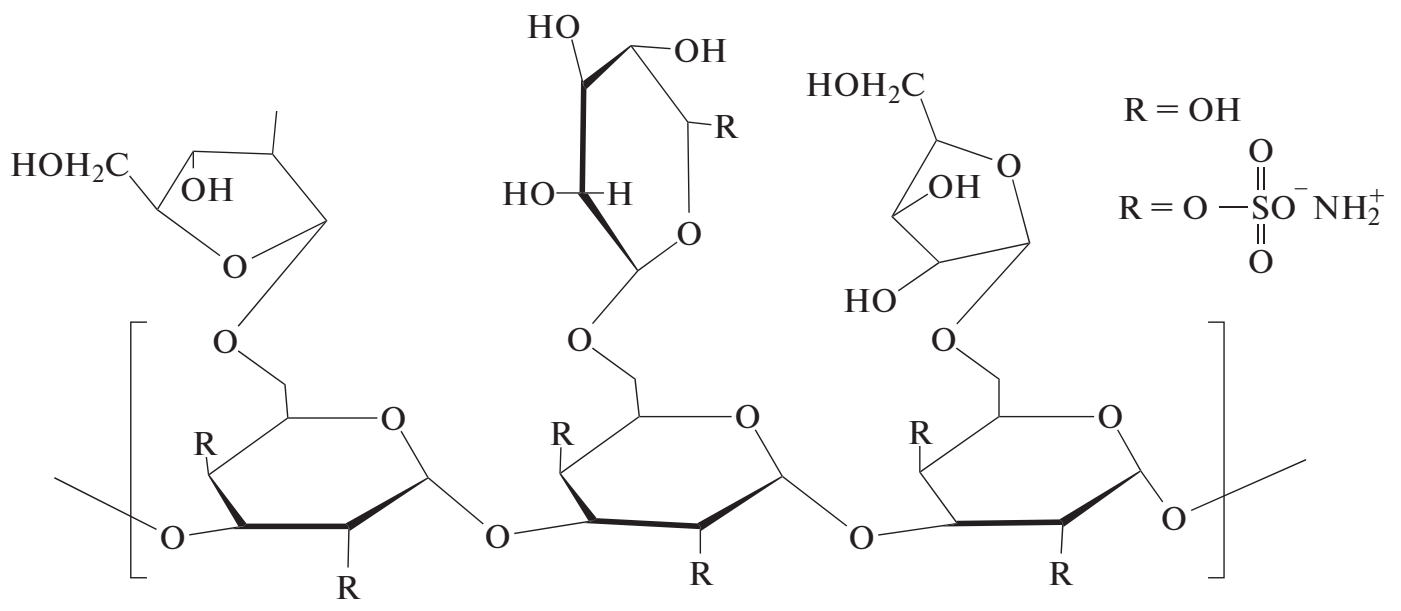

The synthesis of sulfated arabinogalactan was carried out according to the procedure described in [16] by adding sulfamic acid in 1,4-dioxane or dimethyl sulfoxide in the presence of urea under various temperature conditions and the duration of the process, followed by the isolation of SAG in the form of an ammonium salt. To remove unreacted reagents, the product was dialyzed against water for $8-10 \mathrm{~h}$, changing the water every hour. Dialysis was performed using a Cellu Sep T1 cellulose membrane (Membrane Filtration Products Inc., United States) with a molecular weight cutoff of $3.5 \times 10^{3}$. After dialysis, the aqueous SAG solution was evaporated until drying up (Table 1, samples 1, 3, and 4) or to a small volume in vacuum on a rotary evaporator and precipitated into ethanol. The precipitate formed was filtered off, washed on the filter with ethanol, and dried in air (samples 2, 5). Sample 1 was obtained by the sulfation of arabinogalactan in dimethyl sulfoxide at a temperature of $85^{\circ} \mathrm{C}$ for $3 \mathrm{~h}$, samples 2 and 3 were obtained in 1,4-dioxane at $100^{\circ} \mathrm{C}$ also for $3 \mathrm{~h}$, and samples 4 and 5 were obtained in dioxane at $85^{\circ} \mathrm{C}$ for $2 \mathrm{~h}$.

Table 1. Characterization of sulfated arabinogalactan and IPC

\begin{tabular}{|c|c|c|c|c|c|c|}
\hline \multirow{3}{*}{ Sample } & \multicolumn{2}{|c|}{ Sulfated arabinogalactan } & \multicolumn{4}{|c|}{ IPC } \\
\hline & \multirow{2}{*}{$\begin{array}{c}\text { sulfur } \\
\text { content, wt } \%\end{array}$} & \multirow{2}{*}{$\begin{array}{c}\text { degree of } \\
\text { sulfation, \% }\end{array}$} & \multicolumn{2}{|c|}{1 day after synthesis } & \multicolumn{2}{|c|}{30 days after synthesis } \\
\hline & & & size, $\mathrm{nm}(\mathrm{PDI})$ & $\zeta$-potential, $\mathrm{mV}$ & size, $\mathrm{nm}(\mathrm{PDI})$ & $\zeta$-potential, $\mathrm{mV}$ \\
\hline 1 & $13.5 \pm 0.2$ & $40.8 \pm 1$ & $\begin{array}{c}439 \pm 22 \\
(0.17)\end{array}$ & $40 \pm 2$ & $\begin{array}{c}305 \pm 18 \\
(0.19)\end{array}$ & $35 \pm 2$ \\
\hline 2 & $11.7 \pm 0.2$ & $32.4 \pm 1$ & $\begin{array}{c}424 \pm 18 \\
(0.12)\end{array}$ & $39 \pm 2$ & $\begin{array}{c}404 \pm 8 \\
(0.14)\end{array}$ & $34 \pm 3$ \\
\hline 3 & $12.1 \pm 0.2$ & $34.1 \pm 1$ & $\begin{array}{c}426 \pm 31 \\
(0.14)\end{array}$ & $38 \pm 2$ & $\begin{array}{c}377 \pm 11 \\
(0.08)\end{array}$ & $26 \pm 2$ \\
\hline 4 & $4.0 \pm 0.5$ & $8.1 \pm 1$ & $\begin{array}{c}334 \pm 11 \\
(0.20)\end{array}$ & $38 \pm 1$ & $\begin{array}{c}216 \pm 11 \\
(0.12)\end{array}$ & $22 \pm 2$ \\
\hline 5 & $3.8 \pm 0.5$ & $7.7 \pm 1$ & $\begin{array}{c}328 \pm 7 \\
(0.20)\end{array}$ & $38 \pm 4$ & $\begin{array}{c}228 \pm 3 \\
(0.12)\end{array}$ & $32 \pm 3$ \\
\hline
\end{tabular}


The sulfur content and the degree of sulfation of arabinogalactan in the samples were determined according to a modified method [20] by burning them in an oxygen flow at a temperature of $1000^{\circ} \mathrm{C}$ followed by absorption of the products of combustion with a $6 \%$ aqueous solution of hydrogen peroxide. According to [19], the degree of sulfation (DS) was calculated by the formula

$$
\mathrm{DS}=\frac{M_{\mathrm{SAG}} W_{\mathrm{s}} / 100}{\left(M_{\mathrm{S}}-\left(M_{\mathrm{OSO}_{3} \mathrm{NH}_{4}}-M_{\mathrm{OH}}\right) W_{\mathrm{s}} / 100\right) \times 2.8} \times 100 \% .
$$

Here $M_{\mathrm{SAG}}, M_{\mathrm{S}}, M_{\mathrm{OSO}_{3} \mathrm{NH}_{4}}$, and $M_{\mathrm{OH}}$ are the molecular weights of one conventional structural unit of arabinogalactan, sulfur, $\mathrm{OSO}_{3} \mathrm{NH}_{4}$, and $\mathrm{OH}$ groups, respectively; $W_{\mathrm{S}}$ is the sulfur content (wt \%). The results for a series of SAG samples are shown in Table 1.

The degree of deacetylation (DD) of chitosan was determined from the IR absorption spectra according to the procedure [21]:

$$
\mathrm{DD}=100 \%-\frac{A_{1655}}{A_{3430}} \times 100 / 1.33,
$$

where $A_{1655}$ and $A_{3430}$ are the eptical-densities at the corresponding values of wave numbers $\left(\mathrm{cm}^{-1}\right)$.

The technique used for the synthesis of interpolymer complexes was based on the technique previously used in the case of chitosan and another sulfated bio- polymer-chondroitin sulfate at a close $\mathrm{pH}$ value $[22$, 23].

To prepare a solution of chitosan, acetate buffer with $\mathrm{pH} 5.40 \pm 0.03$ and an ionic strength of $0.15 \mathrm{~mol} / \mathrm{L}$ were used. The chitosan solution (0.1 wt \%) was preliminarily purified from insoluble impurities using paper filters, after which a $0.1 \mathrm{wt} \%$ aqueous SAG solution was added dropwise ( $\mathrm{pH} 5.40 \pm$ $0.10)$. The addition of SAG was stopped after the appearance of opalescence of the solution, and the volume ratio of chitosan and arabinogalactan solutions was $2: 1$. The solutions were stirred vigorously with a magnetic stirrer for $2 \mathrm{~h}$. The molecular polymer fraction was separated from the colloidal solution of the interpolymer complexes by sedimentation using an Eppendorf Mini Spin Plus centrifuge (Germany) for 5 min $(14500 \mathrm{rpm})$. After removal of the molecular fraction, the precipitate was resuspended in an Elma Elmasonic S-30H ultrasonic bath (Germany) for $30 \mathrm{~min}$ at room temperature in a buffer-free aqueous solution ( $\mathrm{pH} 5.4 \pm 0.10)$. The concentration of IPCs was estimated by weighing the dry residue: for the entire series of experiments, it was $0.4-0.8 \mathrm{~g} / \mathrm{L}$. According to the average molecular weights of the polymers, the stoichiometric ratio of chitosan macromolecules to sulfated arabinogalactan in IPCs was approximately $1: 3$ :

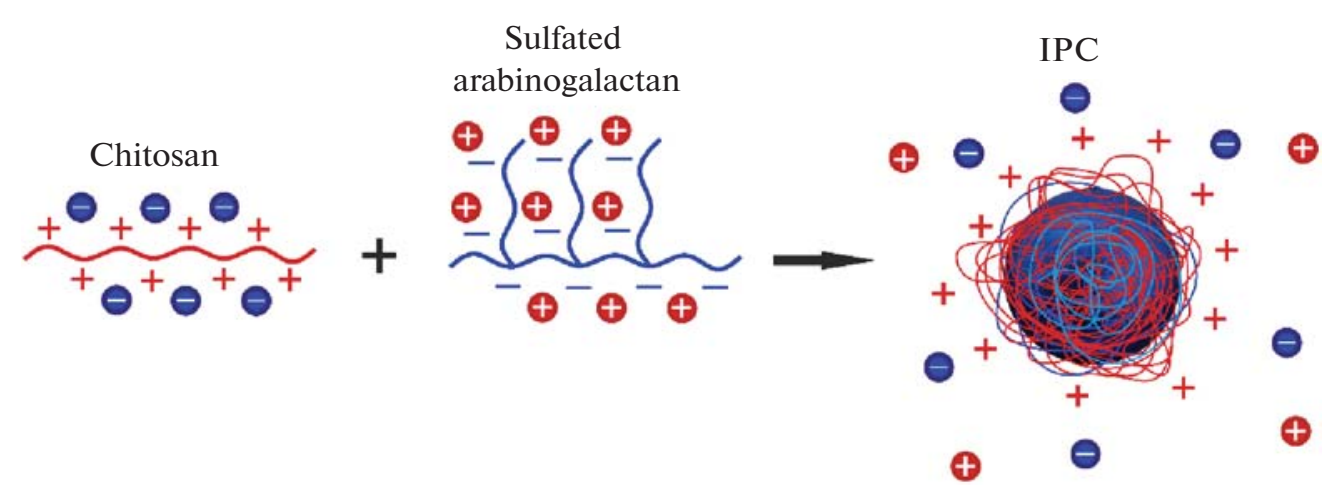

The IR spectra of chitosan, sulfated arabinogalactan, and IPCs were recorded using a Tensor-27 FTIR spectrometer (Bruker, Germany) in the wavelength range of $400-4000 \mathrm{~cm}^{-1}$. Solid samples for analysis were prepared as $\mathrm{KBr}$ pellets ( $\sim 2 \mathrm{mg}$ of sample/1000 $\mathrm{mg}$ of $\mathrm{KBr}$ ). The IR spectra of interpolymer complexes were measured in the first three days after synthesis.

The morphology of IPCs was studied using an S-5500 scanning electron microscope (Hitachi, Japan). For this purpose, a droplet of a dilute IPC solution was applied on a silicon substrate and dried on the first day after synthesis.

The size distribution of IPC particles was performed by dynamic light scattering using a Zetasizer
Nano ZS instrument (Malvern Instruments Ltd., United Kingdom). The scattering angle was $173^{\circ}$; the laser radiation wavelength was $532 \mathrm{~nm}$. Investigations of the autocorrelation function were performed by cumulative analysis. Each sample was measured in three series with twenty repetitions in each series. The $\zeta$-potential of particles was established on the same device by electrophoretic light scattering; data were collected in four series of fifty repetitions each.

\section{RESULTS AND DISCUSSION}

For the synthesis of IPCs, five arabinogalactan samples obtained under various conditions and differing in the degree of sulfation were used (Table 1). 


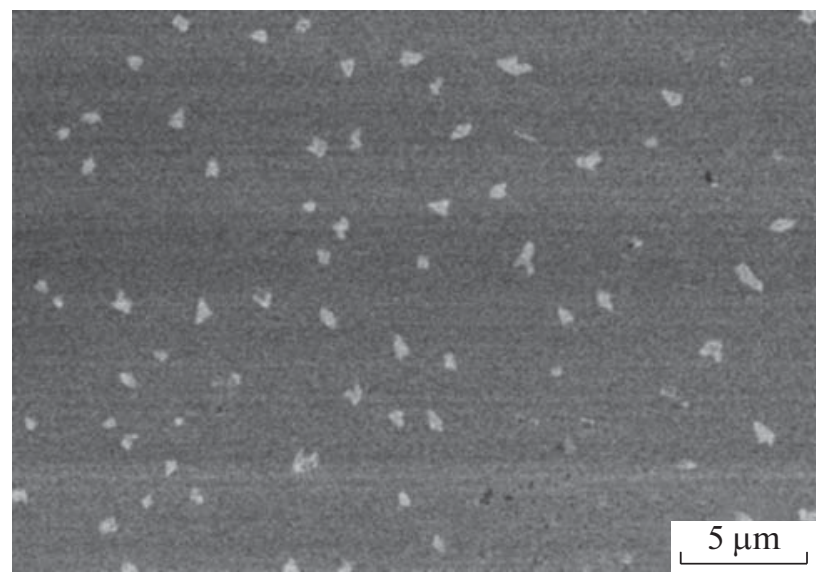

Fig. 1. SEM image.

The formation of complexes is evidenced by the data of scanning electron microscopy (Fig. 1) and IR spectroscopy (Fig. 2). The microgram shows separately located particles of the IPC, inhomogeneous in size and shape in the submicron range.

The IR bands of chitosan and SAG are largely similar owing to their similar structure. Bands typical of polysaccharides can be identified in the ranges of $3435,2921-2924$, and $1047-1075 \mathrm{~cm}^{-1}$. However, the characteristic lines inherent in each polysaccharide separately can be distinguished. Chitosan can be identified using absorption bands due to amide groups: 1656 (Amide I) and $1322 \mathrm{~cm}^{-1}$ (Amide III). An illustrative indicator of sulfate substitution in arabinoga- lactan is the appearance of an absorption peak at $\sim 1241 \mathrm{~cm}^{-1}$ corresponding to $\mathrm{S}=\mathrm{O}$ asymmetric stretching vibrations and a peak at $809 \mathrm{~cm}^{-1}$ characteristic of $\mathrm{C}-\mathrm{O}-\mathrm{S}$ stretching vibrations. In the interpolymer complex, these bands turn out to be displaced in comparison with the initial components because of interactions leading to complexation. The characteristic absorption peaks of Amide I and $\mathrm{S}=\mathrm{O}$ of asymmetric stretching vibrations for the IPCs are at 1633 and $1259 \mathrm{~cm}^{-1}$, respectively. The absorption peak due to Amide III disappears, but no significant shift is found for the peak of $\mathrm{C}-\mathrm{O}-\mathrm{S}$ stretching vibrations.

The size distribution of IPC particles measured on the first day after synthesis is shown in Fig. 3. One can see the unimad particle size distribution with a maximum at $330-440 \mathrm{~nm}$. These data do not contradict the results of microscopic studies. It is characteristic that the particle size correlates with the degree of sulfation of arabinogalactan, which is part of it (Fig. 3, inset).

It should be noted that, on the first day, IPC samples with both low $(7.7-8.1 \%)$ and high degree of sulfation (32.4-40.8\%) have close $\zeta$-potentials $(\sim 40 \mathrm{mV})$. This value satisfies the colloidal stability requirements $(\zeta$-potential $>30 \mathrm{mV}[24])$. Over time, there is a decrease in the size of not only the particles themselves but also their $\zeta$-potential (Fig. 4). In this case, the $\zeta$-potential of the IPCs based on samples 1 , 2 , and 5 decreases by no more than $15 \%$ and does not exceed the critical value for colloid-stable particles, and the $\zeta$-potential of the IPCs based on samples 3 and 4 decreases by $31-42 \%$ and overcomes this

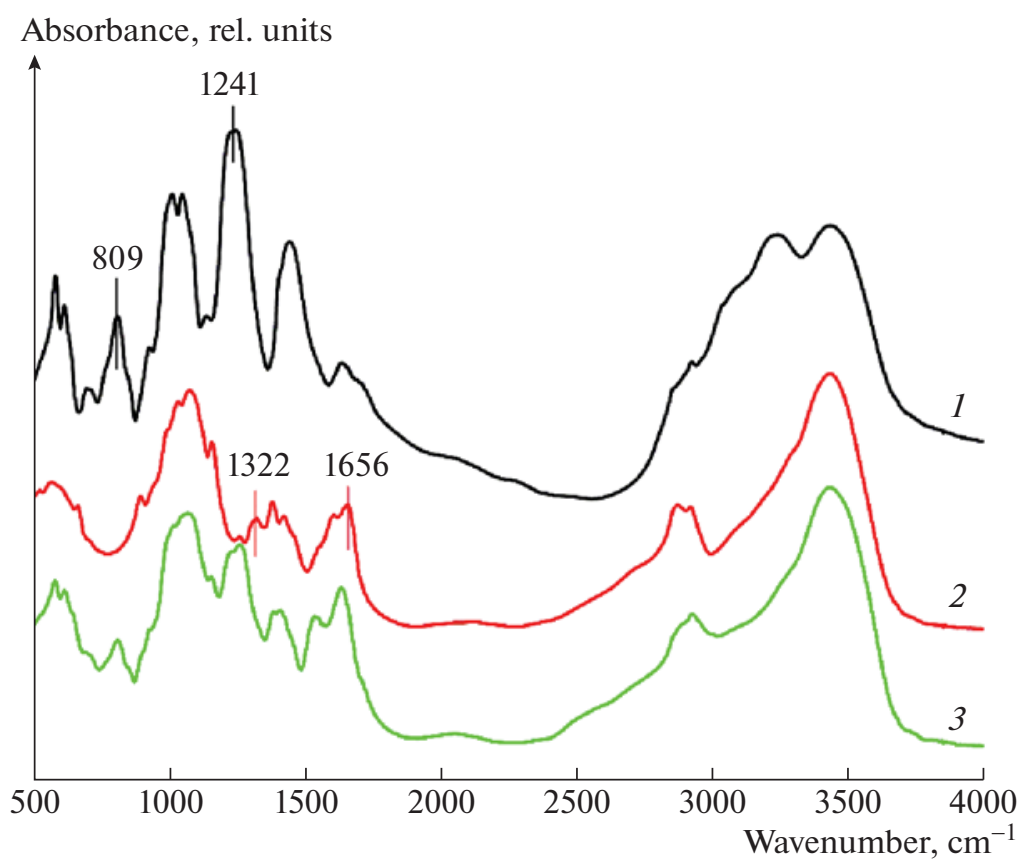

Fig. 2. IR spectra of (1) SAG, (2) chitosan, and (3) the IPC obtained from sulfated arabinogalactan sample 2 in Table 1. 


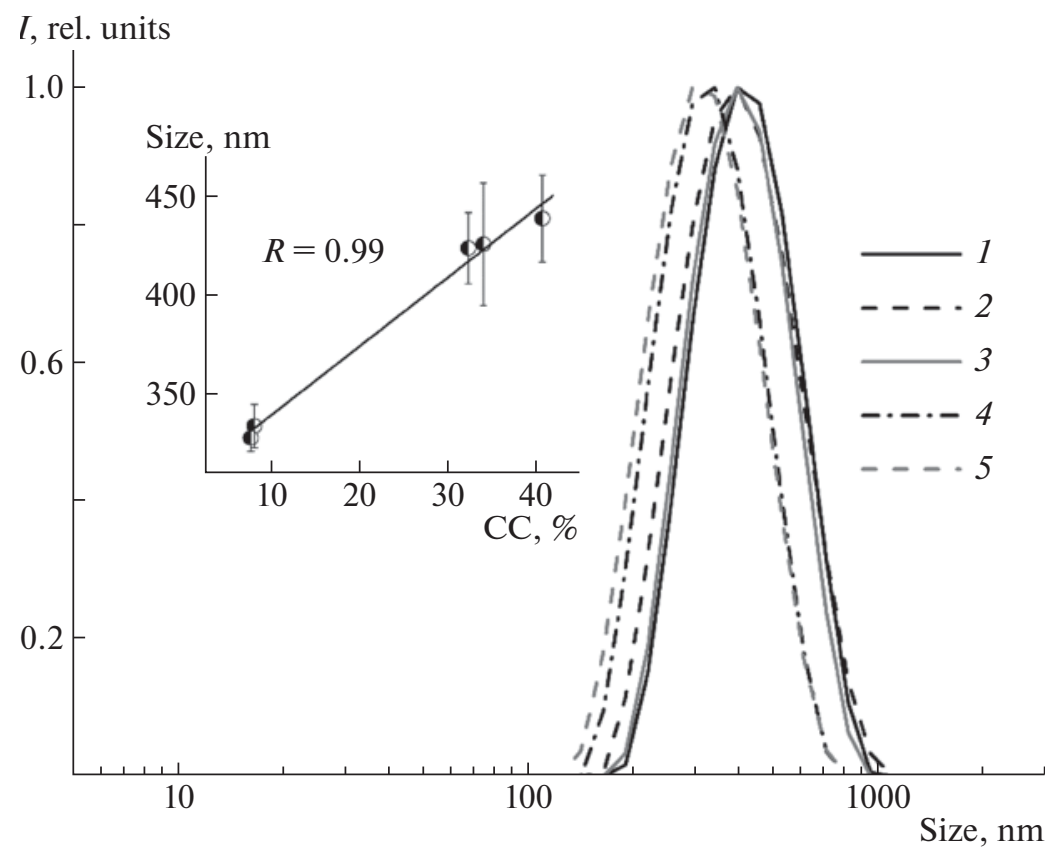

Fig. 3. Size distribution of IPC particles synthesized from sulfated arabinogalactan samples $1-5$ in accordance with Table 1 . The inset shows the dependence of the average size of the IPC on the degree of SAG included in its composition.

threshold. These results do not correlate with the degree of sulfation of arabinogalactan and may be associated with the method of synthesis of SAG. For example, the highest stability was exhibited by not precipitated samples and the sample synthesized using dimethyl sulfoxide. Presumably, this is due to the specificity of precipitating SAG, which can indirectly affect the molecular weight of the selected polysaccharide fraction, as well as due to the residues of synthesis precursors.

A decrease in particle size over time is possible due to their colloidal instability and the precipitation of the largest of them. However, the IPCs based on samples 2 and $3(5-12 \%$ change) turned out to be the smallest dimensional changes, while the average particle size for the IPCs based on samples 1, 4, and 5 decreased by $30-35 \%$. This indicates a more complex relationship between the dimensional stability and the $\zeta$-potential. As shown in [25], the formation of polyelectrolyte complexes occurs via several stages: the initial formation of polyelectrolyte complexes, the formation of new internal bonds, and the intercomplex aggregation. Separating these steps is a challenge. The parameters of particle stability obtained in the present work (e.g., for sample 2 , the change in size and $\zeta$-potential for 30 days does not exceed 5 and $15 \%$, respectively) are comparable or improved in comparison with other polyelectrolyte complexes based on chitosan [26, 27].

The formation of the IPCs is considered in terms of analysis of the electrostatic mechanism of binding of two biopolymers. A similar quantitative analysis was made in [26]. The efficiency of electrostatic binding depends on the number of charged groups of biopolymers determined by dissociation constants under given conditions $\left(\mathrm{p} K_{a}\right)$. For example, the value of $\mathrm{p} K_{a}$ for the amino groups of chitosan is 6.2-6.8 [28]. For arabinogalactan suffe groups, it can be taken to be $1.5-2.0$ by analogy with chondroitin sulfate sulfo groups [29]. The degree of dissociation of $\alpha$ polyelectrolytes is expressed by the Henderson-Hasselbalch equation, which describes the relationship between $\mathrm{pH}$ and $\mathrm{p} K_{a}$ :

$$
\mathrm{pH}=\mathrm{p} K_{a}+\log \frac{\alpha}{1-\alpha} .
$$

According to this equation, at $\mathrm{pH} 5.4$, the value of $\alpha$ for chitosan is $75 \%$; for SAG, $78 \%$. Given the average molecular weights of the polymers, the degree of chitosan deacetylation ( $88 \%$ ), and the degree of sulfation of arabinogalactan $(7.7 \%-40.8 \%)$, as well as the mass ratio of the biopolymers upon mixing, the ratio of positively charged chitosan groups to negatively charged SAG groups is from $4: 1$ to $21: 1$. A mixture of oppositely charged polyions leads to the formation of nonstoichiometric complexes, which usually consist of a neutral core and excess polyion chains [30]. Since the positively charged amino groups of chitosan are in excess compared to negatively charged SAG groups, the $\zeta$-potential of the particles is positive.

An increase in the size of IPCs (Fig. 3) and the broadening of particle size distribution with increasing degree of sulfation (for samples with a low degree of sulfation, the half-width at half-height is $340 \mathrm{~nm}$; for samples with a high degree of sulfation, $410-420 \mathrm{~nm}$ ) 

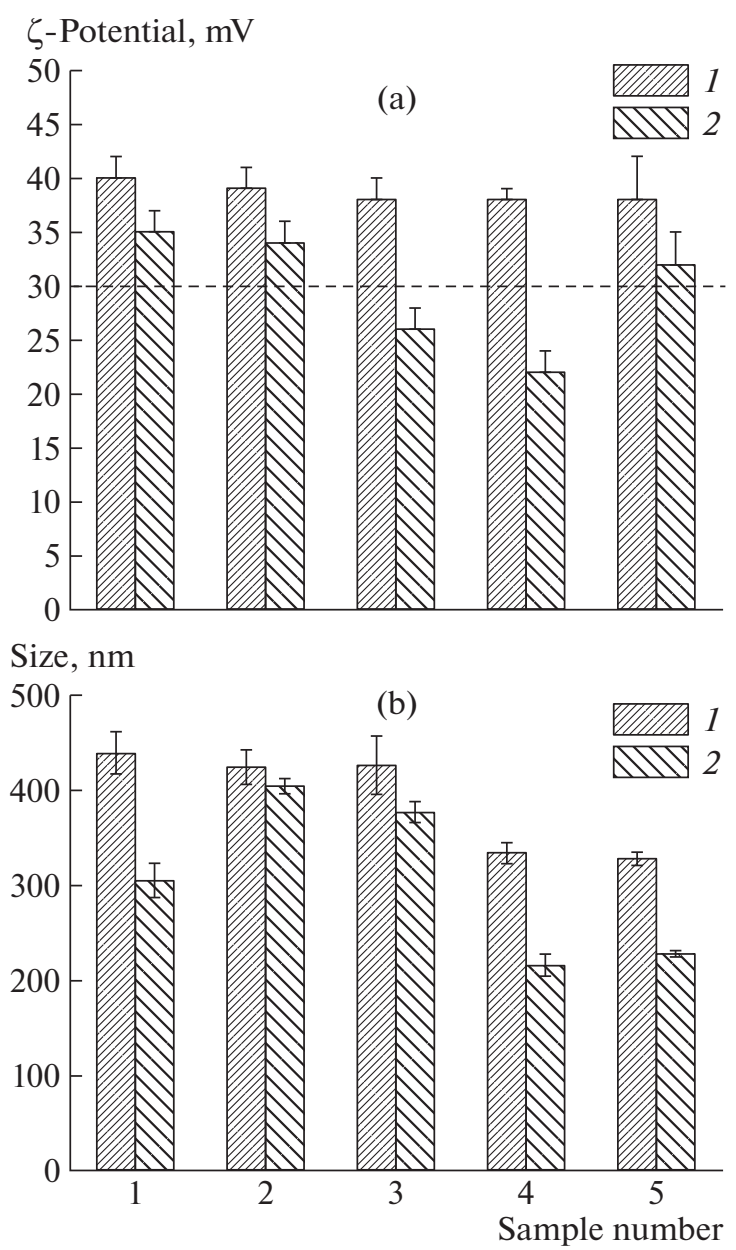

Fig. 4. (a) $\zeta$-Potential and (b) size of IPCs synthesized from sulfated arabinogalactan samples in accordance with Table 1: (1) 1 day and (2) 30 days after synthesis. The dashed line shows the level that meets the requirement of colloidal stability.

indicate that the formation of particles with a high degree of sulfation involves a larger number of polysaccharide molecules and/or particles have a looser structure. In addition, the formation of such complexes depends not only on electrostatic but also on hydrophobic interactions. Earlier [30], this was shown by the example of complexation of sulfo derivatives of lignin and chitosan.

The resulting interpolymer complexes have a positive surface charge, have stable colloidal properties, and contain biopolymers with known biological activity. Similar systems can be used as biosorbents of organic compounds or heavy metals, as well as drug delivery systems [31-33].

\section{ACKNOWLEDGMENTS}

We are grateful to the Krasnoyarsk Regional Shared Research Center, Krasnoyarsk Scientific Center, Siberian
Branch, Russian Academy of Sciences, for taking IR spectra and performing microscopic measurements.

\section{FUNDING}

The study was supported by the Russian Foundation for Basic Research, the government of the Krasnoyarsk krai, and the Krasnoyarsk Regional Science Foundation (project no. 18-43-242003).

\section{REFERENCES}

1. J. Berger, M. Reist, J. M. Mayer, O. Felt, and R. Gurny, Biopharmaceutics 57, 35 (2004).

2. W. L. Du, Z. R. Xu, X. Y. Han, Y. L. Xu, and Z. G. Miao, J. Hazard. Mater. 153, 152 (2008).

3. R. Wang, X. Jiang, A. He, T. Xiang, and C. Zhao, RSC Adv. 5, 51631 (2015).

4. M. Prabaharan and F. J. Mano, Drug Delivery 12, 41 (2004).

5. M. A. Krayukhina, N. A. Samoilova, and I. A. Yamskov, Russ. Chem. Rev. 77, 799 (2008).

6. G. V. Kumar, C.-H. Su, and P. Velusamy, Mater. Lett. 12, 119 (2016).

7. C. K. Lai, Y. L. Lu, J. T. Hsieh, S. C. Tsai, C. L. Feng, Y. S. Tsai, P. C. Tsai, H. L. Su, Y. H. Lin, and C. H. Lai, Nanomedicine (London, U. K.) 9, 803 (2014).

8. A. Grenha, M. E. Gomes, M. Rodrigues, V. E. Santo, J. F. Mano, N. M. Neves, and R. L. Reis, J. Biomed. Mater. Res., Part A 92, 1265 (2010).

9. S. Rodrigues, A. M. Rosa Da Costa, and A. Grenha, Carbohydr. Polym. 89, 282 (2012).

10. T. A. Abdullah, N. J. Ibrahim, and M. H. Warsi, Int. J. Pharm. Invest. 6, 96 (2016).

11. V. E. Santo, M. E. Gomes, J. F. Mano, and R. L. Reis, J. Tissue Eng. Regener. Med. 6, 47 (2012).

12. E. Lallana, RosaJ. R. De La, A. Tirella, M. Pelliccia, A. Gennari, I. Stratford, S. Puri, M. Ashford, and N. Tirelli, Mol. Pharmaceut. 14, 2422 (2017).

13. Ya. N. Kostyro, O. A. Silizertseva, A. I. Iskra, E. N. Petrova, L. B. Koryakina, S. A. Vereshchagina, T. B. Fadeeva, K. V. Alekseev, E. N. Gumennikova, V. V. Kostyro, T. V. Ganenko, V. K. Stankevich, and B. A. Trofimov, Byull. VSNTs SO RAMN 80, 249 (2011).

14. E. N. Medvedeva, V. A. Babkin, and L. A. Ostroukhova, Khim. Rastit. Syr'ya, No. 1, 27 (2003).

15. T. Ehrenfreund-Kleinman, A. J. Domb, and J. Golenser, J. Bioact. Compat. Polym. 18, 323 (2003).

16. N. Y. Vasil'eva, A. V. Levdanskya, B. N. Kuznetsova, G. P. Skvortsova, A. S. Kazachenko, L. Djakovitch, and C. Pinel, Russ. J. Bioorg. Chem. 41, 725 (2015).

17. Ya. A. Kostyro and G. N. Koval'skaya, Byull. VSNTs SO RAMN 60, 117 (2008).

18. N. N. Drozd, S. A. Kuznetsova, E. S. Lapikova, A. I. Davydova, V. A. Makarov, B. N. Kuznetsov, A. I. Butylkina, N. Yu. Vasil'eva, and G. P. Skvortsova, Eksp. Klin. Farmakol. 71 (4), 30 (2008). 
19. N. D. Cheronis and T. S. Ma, Organic Functional Group Analysis by Micro and Semimicro Methods (Interscience, New York, 1964).

20. V. A. Babkin, N. A. Neverova, K. N. Medvedeva, T. E. Fedorova, and A. A. Levchuk, Khim. Rastit. Syr'ya, No. 2, 29 (2015).

21. R. Czechowska-Biskup, D. Jarosińska, B. Rokita, P. Ulański, and J. M. Rosiak, Prog. Chem. Appl. Chitin Its Deriv. 17, 5 (2012).

22. E. Slyusareva, M. Gerasimova, A. Plotnikov, and A. Sizykh, J. Colloid Interface Sci. 417, 80 (2014).

23. E. Slyusareva, M. Gerasimova, V. Slabko, N. Abuzova, A. Plotnikov, and A. Eychmiller, Phys. Chem. Chem. Phys 16, 3997 (2015).

24. S. Boddohi, N. Moore, P. A. Johnson, and M. J. Kipper, Biomacromolecules 10, 1402 (2009).

25. A. D. Kulkarni, Y. H. Vanjari, K. H. Sancheti, H. M. Patel, V. S. Belgamwar, S. J. Surana, and C. V. Pardeshi, Artif. Cells, Nanomed., Biotechnol. 44, 1615 (2016).
26. N. Slyusarenko, M. Gerasimova, A. Plotnikov, N. Gaponik, and E. Slyusareva, Phys. Chem. Chem. Phys. 21, 4831 (2019).

27. H. Jonassen, and A. -L. Kjøniksen, and M. Hiorth, Biomacromolecules 13, 3747 (2012).

28. R. Schmuhl, H. M. Krieg, and K. Keizer, Water SA 27, 1 (2001).

29. P. Chandran and F. Horkay, Acta Biomater. 8, 3 (2012).

30. I. A. Palamarchuk, O. S. Brovko, T. A. Boitsova, A. P. Vishnyakova, and N. A. Makarevich, Khim. Rastit. Syr'ya, No. 2, 57 (2011).

31. G. Z. Kyzas, D. N. Bikiaris, and A. C. Mitropoulosa, Polym. Int. 66, 1800 (2017).

32. D. Hritsu, G. Dodi, and M. I. Popa, IRECHE 4, 364 (2012).

33. A. Bernkop-Schnürch and S. Dunnhaupt, Eur. J. Pharm. Biopharm 81, 463 (2012). 